\title{
Expression of Concern to: Decreased microRNA-224 and its clinical significance in non-small cell lung cancer patients
}

Dan Zhu*, Hui Chen, Xiguang Yang, Weisong Chen, Linying Wang, Jilin Xu and Long Yu

\section{Expression of Concern: Diagn Pathol (2014) 9:198}

DOI 10.1186/s13000-014-0198-4

The Editor-in-Chief is issuing an editorial expression of concern to alert readers that the article, Decreased microRNA-224 and its clinical significance in non-small cell lung cancer patients, Diagnostic Pathology 2014 9:198 [1] contains substantial overlap with article MiR-206 functions as a tumor suppressor and directly targets K-Ras in human oral squamous cell carcinoma Lin et al. in Onco Targets Therapy 2015; 8: 1773-1783 and Fig. 3 shows similarity to Fig. 3 in article, Decreased microRNA-452 expression and its prognostic significance in human osteosarcoma, World Journal of Surgical Oncology 2016, 14:8. As the authors have not responded to correspondence asking them for an explanation, this matter has now been referred to the authors' institution for further investigation.

Published online: 30 May 2019

\section{Reference}

1. Dan Z et al. Decreased microRNA-224 and its clinical significance in nonsmall cell lung cancer patients. Diagn Pathol. 2014;9:198. https://doi.org/10 1186/s13000-014-0198-4

\footnotetext{
* Correspondence: manuzhudan@163.com Jinhua 321000, People's Republic of China
} 